$\xi=-1$

\title{
Effect of SBI Bank Merger on Education Loan, a Comparative Study Using Big Data Analytics
}

\author{
Anjali mathur' ${ }^{1}$, K.Vinitha ${ }^{2}$, R.Shubham ${ }^{3}$, K.Gowtham ${ }^{4}$ \\ ${ }^{1,2,3,4}$ Department of CSE, KLEF, Guntur, India \\ *Corresponding author E-mail: anjali mathur@kluniversity.in
}

\begin{abstract}
A bank merger is a situation in which two banks or all branches of a bank join together to become one bank. The bank merger of State Bank of India was implemented on 1stApril 2017 in India. The bank merger is a good idea to centralize the customer's data from nationwide. However, it is a difficult task for administrators and technologists. Some high level techniques are required to collect the data from the branches, of the bank present at nationwide, and merge them accordingly. For this huge data Big-Data Analysis techniques can be used to manage and access the data. The big data analytics provides algorithms to compare, classify and cluster the data at local and global level. This research paper proposes big data analytics for education loan provided by State Bank of India. The loan granting process becomes centralized after merger. It affects the processing of granting a loan, as earlier it was according to branches only. The proposed work is for comparative study of the impact of bank merger on education loan provided by State Bank of India.
\end{abstract}

Keywords:Merger \& Acquisition (M\&As), logistic regression, mean, deviation, ANOVA..

\section{Introduction}

Bank is introduced [2] to as a financial organization or a partnership which is approved by the state or the local administration to manage the cash by tolerating stores, giving credits and giving security to the cash kept by the client in the bank[1]. The fundamental parts of banks are financial aspects development, extension of the economy and give assets to venture. In the current circumstances managing an account part has experienced a considerable measure of changes as far as direction and impacts of globalization. They have adopted many different strategies to remain effective and to move ahead in the worldwide dome. Among the different strategies adopted by State Bank of India, bank merger is one of the major strategy. The motive behind this paper is to discover several reasons for mergers in the Indian banking sector. This contains several characteristics of bank mergers and It also relates the financial performance of previous and subsequent mergers, such as gross income, net profit, operating profit, return on capital, and debt ratios. Through the literature, it is reviewed that it is aware that a large amount of work has been done on the impact of mergers and acquisitions in several companies. Data on mergers and acquisitions such as economic liberalization are collected for different [3]financial parameters. The independent $\mathrm{T}$ test used for the statistical tests and this test applies not only to the correlation analysis, but also to the impact of the mergers on the performance of the banks. This performance is tested on two bases, namely, initiation and merging. Finally, the study shows that banks have had a positive impact on mergers. The main reason for mergers and acquisitions [2] in the banking system to achieve economies of scale and scope. Mergers also help to diversify the product, which helps reduce risk. This obtaining firm has a tendency to be bigger than target firms to control for bank measure in our tests. We measure estimate utilizing the bank's aggregate resources. We likewise control for banks' normal branch estimate. Branch measure is proposed to catch two impacts. Manages an account with numerous little workplaces may make alluring targets on the grounds that disposing of repetitive branches offers more noteworthy solidification benefits. Keeps money with some little branches may likewise be alluring targets since they permit an acquirer to enter another market rapidly. At long last, we control for banks' past execution. Controlling for execution is vital to lessen excluded variable predispositions.

\section{Literature Survey}

One experimental investigation was conducted [1] to break down the consequences of M\& As from the budgetary perspective. The work was based on certain parameters like liquidity, use, gainfulness. The Authors watched out that if a wiped out firm is assumed control by a decent administration and makes genuine endeavors, it is conceivable to turn it around effectively. An analytical work was carried out during the time period of 1992 to 1995 to distinguish the money related attributes for the organizations which get merged. The analysis distinguished the profile of the benefits. The M\&As suggested that the firms which are yet to be combined were inferior when compared with combined firms in terms of development, duty, and flow of the business were apprehensive. The combined firms performed superior when compared to the firms that were not yet merged. In another research work an investigation was carried out on the basis of for business traditions, i.e. [3] "Working Execution and the Strategy for Installment in Takeovers". The paper represents the connection between the techniques for installment, income administration, along with operation. In that work examination was carried out that depends upon an example of 959 M\&As (mergers and delicate offers) variables. The examination suggested that obtaining firms show better operation in respect to their industry partners before merger and keep 
on showing higher execution levels with respect to their individual projects; authors were unable to find out the proof for the effects of income administration ; differences for various strategies for the installment of operations.

One more work was proposed for [4] financial Execution of Indian Assembling Organizations before and after merger. The authors make use of $30 \%$ of firms from the combined population, as a sample. The methodology used in that work was proportion investigation, standard deviation, mean and $\mathrm{t}-$ test. An investigation was carried out [5] to show the effect of merger along with the acquisition on corporate execution in India. The investigation proposed a method to check whether the cases made by the business part were profitable through M\&As to make joint efforts were being refined or not according to Indian environment. Authors focused on the effect of M\&As on the cash related execution of the results. The work displays that according to time the results of merger oversees securing deals. The investigation utilized proportions and relationship framework for examination, and discovered that the gaining firms could produce collaboration over the long haul. That generates the higher income, more business, enhancement and cost cuttings.

One research work was carried out to show the merger effect at Australia [6], Authors analyzed the operation of combined companies contrasted regarding the implementation of the pre-merger targets and acquirers. Implementation procedures which was used for the examination was benefit, pay, capability, utilize, and improvement. Such measures were used to deliver the achievement of the M\&As, which is used to describe the level of extent that an adjustment in each mixed affiliation's business agreed Operation between the time period pre-and post-merger. The examination gave a couple of demonstrate that M\&As upgraded post-merger Operation

[7] In a work authorized "Post-merger Company Execution: An Indian Point of view" analyzed the post-merger Operation of an example of 30 securing firms engaged with M\&As exercises amid in India. The examination endeavored to distinguish collaborations, assuming any, subsequent from mergers. The examination used accounting data to take a gander at [1]M\&As- related increments to the acquiring corporations. It was initiate that postmerger efficiency, properties income, and dissolvability of the obtaining companies exhibited no change when differentiated and pre-merger regards.

[8] In an investigation of "Merger and Acquisitions" - An Experimental Investigation on before and after obtaining Execution of Chose Indian Business Segment Ventures" investigated the effect of M\&As on the execution of chose corporate segment ventures in four enterprises gatherings in India. The investigation has utilized auxiliary information to break down the results of M\&As execution of the 117 getting firms and for this reason the information gathered traverses more than 12 years going from 1994-95 to 2005-06. The examination utilized factual apparatuses, to be specific, incline examination, one way ANOVA, factor investigation, what's more, bunch examination. The examination demonstrated that the post-securing execution of the obtaining firms' productivity, resources use, obligation usage, cost usage, fluidity, [1] and capital structure had not consistently changed taking all things together the example ventures. The flat, vertical, and aggregate M\&As had no uniform effect to change the post-obtaining execution of the example businesses. Be that as it may, flat M\&As have more prominent impact in progressing the post-procurement execution when contrasted and the other two sorts of M\&As, specifically, vertical and combination.

In an study of [1]"Merger and Acquisitions" An Observational Examination on the Transient Post-merger Execution of Corporate companies in India" endeavored to investigate the effect of M\&As with a test of 20 companies were recorded as one of the main Indian stock trades, explicitly in the Bombay Stock Trade. The examination went for contrasting the liquidity execution of the ex- ample securing firms utilizing proportion investigation and two examples matched t-test amid the examination time of three years before the merger and three years after the merger. The examination utilized money related proportions to gauge the corporate execution of pre-and post-merger, for instance, current extent, energetic extent, working capital extent, net advantage extent, working advantage extent, return on hypothesis extent, add up to resources extent, account holders turnover extent, settled assets turnover extent, signify assets turnover extent, working capital turnover extent, commitment esteem extent, interest scope extent, and total getting and incentive to EBITD.

The main aim behind this comparative study is to know about the profits that bank will get after merging with five different associate banks. The purpose is to study the impact of bank merger on education loan provided by [4] State Bank of India.

\section{Methodology}

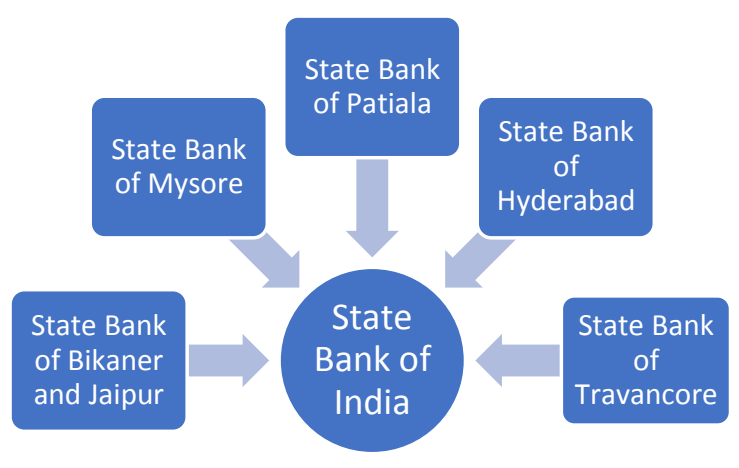

The statistical methods such as Mean, Standard deviation and logistic regression by using correlation, are commonly used for any comparative study. Correlation is a technique used to find out the relation between two variables. It can find out the dependency of one variable on another. [11] Regression is a technique used to predict the next continues value based on some variables. Regression can be representing in any one of two techniques:-linear and non-linear. Linear Regression shows the relation between two variables. Non-Linear Regression represents the dependency of one variable on one or more independent variables. The observational data is modified with the help of a function which is a nonlinear combination of the given parameters. Logistic regression is a technique used for analyzing datasets which consists of one or more than one independent variables that gives us an outcome. [12] Anova means analysis of variance. It is performed on set of statistical models and their associated processes. This test is used to analyze the differences among the several groups of data. It provides the result of the statistical test by checking whether the mean values of several group of data are equal or not.

The analyses steps include in this work are:

\section{a. Data Collection, \\ b. Data Cleaning, \\ c. Data Modeling}

a. Data collection: In this step data is collected from bank which includes the details about customers as well as loan and credit. For this study we collected the data from State Bank of India and tried to collect some data from those branches which are merged.

b. Data cleaning: The data cleaning is done by handling missing data and deleting the useless information. This is one of the important step because the presence of useless data will generate the wrong results. In this study the data cleaning process includes the 
details of only those customers who applied for the loan. From the loan details we clean all the details except education loan.

c. Data modeling: In this step the models are built to correlate the attributes available in the dataset. Various statistical techniques are available for model building, as, mean calculation, finding standard deviation, performing ANOVA test and T-test.

\section{Observations and Results}

We collected the bank data of nearly 10,000 customers and calculated the sum of loan amount. The bank data consists of customer name, age, gender, purpose of loan, loan amount, number of installments, interest rate. These details are shortly described in Table- 1 and in Table- 2 .

The loan amount is differentiated into two different categories based on the date of loan sanction, either before or after the merger. The technique used to show the difference in the performance of banking system is logistic regression. The outcome is measured with a dichotomous variable that shows us that there are only two possible outcomes. The output is in the form of graphical representation. $\mathrm{X}$ axis of the graph denotes the sum of loan amount and $\mathrm{Y}$ axis denotes the deviation. Since it is the statistical data and logistic regression is the statistical method of analyzing the dataset, the sum of loan amount and standard deviation are to be calculated. The difference between the sum of loan and the standard deviation is necessary to plot the graph that shows the outcome.

Table 1: Details before Bank merger

\begin{tabular}{|l|c|c|c|}
\hline Loan ID & $83721 \mathrm{ffb}$ & 08f3789f & a4957169 \\
\hline Loan Amount & 176242 & 321992 & 202928 \\
\hline Term & Short Term & Short Term & Short Term \\
\hline Credit Score & 727 & 744 & 741 \\
\hline Months & 120 & 120 & 12 \\
\hline Purpose & $\begin{array}{c}\text { Abroad edu- } \\
\text { cation }\end{array}$ & $\begin{array}{c}\text { Vocational } \\
\text { education }\end{array}$ & $\begin{array}{c}\text { Premier Indian } \\
\text { education }\end{array}$ \\
\hline $\begin{array}{l}\text { No of Open } \\
\text { Accounts }\end{array}$ & 16 & 14 & 6 \\
\hline $\begin{array}{l}\text { No of Credit } \\
\text { Problems }\end{array}$ & 1 & 0 & 0 \\
\hline Bankruptcies & 1 & 0 & 0 \\
\hline Status & Individual & Individual & Individual \\
\hline
\end{tabular}

Table 2: Details after Bank merger

Table 2: Details after Bank merger
\begin{tabular}{|l|c|c|c|}
\hline Loan ID & f738779f & 6 dcc0947 & f7744d01 \\
\hline Loan Amount & 611314 & 266662 & 153494 \\
\hline Term & Short Term & Short Term & Short Term \\
\hline Credit Score & 747 & 734 & 709 \\
\hline Months & 120 & 120 & 24 \\
\hline Purpose & $\begin{array}{c}\text { Abroad edu- } \\
\text { cation }\end{array}$ & $\begin{array}{c}\text { Vocational } \\
\text { education }\end{array}$ & $\begin{array}{c}\text { Premier Indian } \\
\text { education }\end{array}$ \\
\hline $\begin{array}{l}\text { No of Open } \\
\text { Accounts }\end{array}$ & 9 & 11 & 10 \\
\hline $\begin{array}{l}\text { No of Credit } \\
\text { Problems }\end{array}$ & 0 & 0 & 0 \\
\hline Bankruptcies & 0 & 0 & 0 \\
\hline Status & Merged & Merged & Merged \\
\hline
\end{tabular}

$\operatorname{Mean}(\bar{X})$ :

$\bar{X}=\frac{\sum X}{n}$

$\bar{X}=$ mean of all the loan amount values in the dataset.

$\mathrm{X}=$ each loan amount value in the dataset.

$\mathrm{n}=$ number of loan amount values in the dataset.

$\Sigma=$ sum of. Mean value for before merger data:

$\sum X=701162$

$\mathrm{n}=3$
$\bar{X}=\frac{701162}{3}$
$\bar{X}=233720.67$.

Mean value for after merger data:

$\sum X=1031470$

$\mathrm{n}=3$

$\bar{X}=\frac{1031470}{3}$

$\bar{X}=343823.34$

Deviation(S):

$\mathbf{S}=\sqrt{\frac{(X-\bar{X})^{2}}{n}}$

$\mathrm{S}=$ the standard deviation of the sample.

$\bar{X}=$ mean of all the loan amount values in the dataset.

$X=$ each loan amount value in the dataset.

$\mathrm{n}=$ number of loan amount values in the dataset.

$\sum=$ sum of.

Deviation of before merger sample data:

$\mathrm{X}=321992$

$\bar{X}=233720.67$

$(X-\bar{X})^{2}=7791827700$

$\mathrm{n}=3$

$\mathrm{S}=\sqrt{\frac{7791827700}{3}}$

$\mathrm{S}=50963.47$

Deviation of after merger sample data:

$X=266662$

$\bar{X}=343823.34$

$(X-\bar{X})^{2}=5953872391$

$\mathrm{n}=3$

$\mathrm{S}=\sqrt{\frac{5953872391}{3}}$

$\mathrm{S}=44549.12$

Table 3: Comparison of Standard Deviation before and after Bank merger Profit in loan amount before merg- $\quad$ Profit in loan amount after merging

\begin{tabular}{ll} 
Sum $=55271836255$ & Sum $=607661758888$ \\
\hline & Deviation $=32255437$
\end{tabular}

\begin{tabular}{|l|l}
\hline Deviation $=30917884$ & Deviation $=32255437$ \\
\hline Difference $=9.559156 \mathrm{e}+14$
\end{tabular}

Difference $=9.559156 \mathrm{e}+14 \quad$ Difference $=1.040413 \mathrm{e}+15$

From the above table- 3 the logistic regression graph is plotted $\mathrm{X}$ axis is performance (sum of loan amount) and $y$-axis is variance (scaled with an interval from 0.0 to 1.0 )

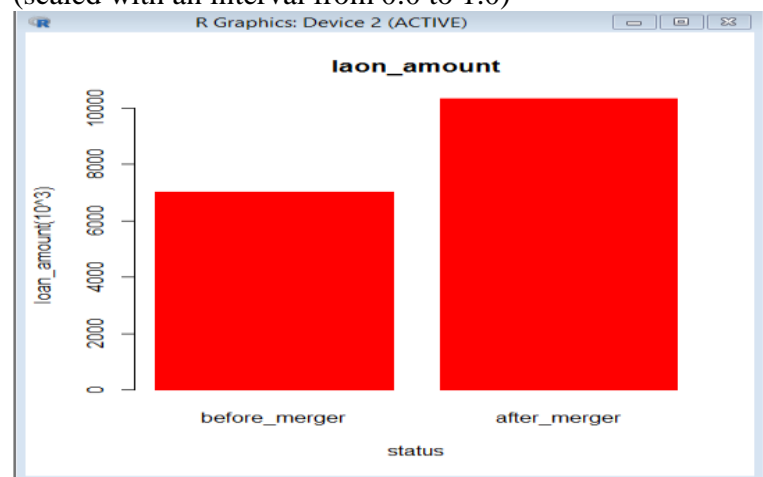

Figure 1: comparison of loan amount

When the datasets are compared for the attribute 'Loan amount', we get the graph as shown in figure 1 . In the graph $\mathrm{x}$-axis represents status of the bank(individual, merged) and y-axis represents loan amount $\left(10^{3}\right)$. 


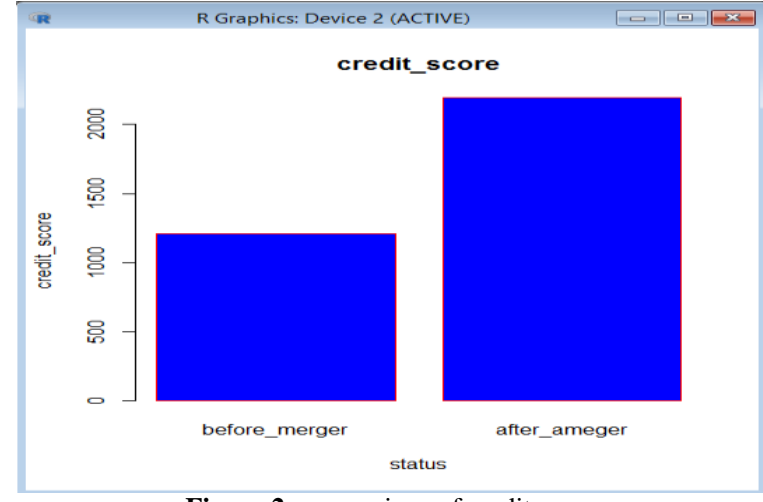

Figure 2: comparison of credit score

When the datasets are compared for the attribute 'Credit score', we get the graph as shown in figure 2 . In the graph $\mathrm{x}$-axis represents status of the bank(individual, merged) and $y$-axis represents credit score.

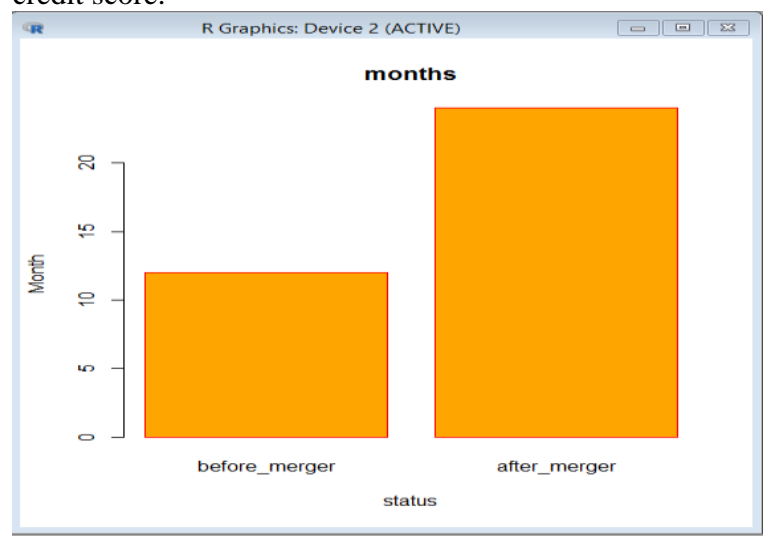

Figure 3: comparisons of loan repay duration

When the datasets are compared for the attribute 'loan repay duration', we get the graph as shown in figure 3. In the graph x-axis represents status of the bank (individual, merged) and y-axis represents loan repay duration.

\section{Conclusion}

Logistic regression is used to analyze various datasets for the big data. Analysis is done between one or more variables. In future several new financial institutions will be created on the basis of this study. Merged banking systems have become highly competitive and profitable sectors. The flexibility in the banking sector has increased the need to make important repairs and effective economic system and the opportunities of the economic growth have increased.

\section{References}

[1] Online reference 'shodhganga.inflibnet.ac.in'

[2] Mergers in Indian Banks: A Study on Mergers of HDFC Bank limited Centurion Bank of Punjab.

[3] Shankar, R., and K. V. Rao. 1998. Takeovers as a strategy of turnaround - An empirical study. The Indian Journal of Commerce 51: 47-56

[4] Pawaskar, V. 2001. Effect of mergers on corporate perfor-mance in India Vikalpa 26 (1), (January-March): 19-32

[5] .Heron, R., and E. Lie. 2002. Operating performance and the method of payment in takeovers. Journal of Financial and Quantita-tive Analysis37(1), (March): 137-56.

[6] Kumar, S., and L. K. Bansal. 2008. The impact of mergers and acquisitions on corporate performance in India. Management Decision 46(10):1531-43.
[7] Lau, B., A. Proimos, and S. Wright. 2008. Accounting measures of operating performance outcomes for Australian mergers. Journal of Applied Accounting 9(3):168-170.

[8] Kumar, R. 2009. Post-merger corporate performance: An Indian perspective. Management Research News 32(2): 145-57.

[9] Pazarskis, M., T. Karagiorgos, I. Elaterids, and P.Christodoulou.2010. The post-merger performance of Greek acquiring listed firms: An accounting analysis. MIBES Transac-tions 4(1), (Spring): 96-107.

[10] .Online reference 'https://www.acmeintellects.org/images/AIIJRMSST/Jan2016/4-116.pdf'

[11] Online reference'https:// explorable.com/multiple-regressionanalysis'

[12] .Onlinereference'https://en.wikipedia.org/wiki/Analysis_of_varianc e'. 